\title{
Minocycline corrects early, pre-plaque neuroinflammation and inhibits BACE- 1 in a transgenic model of Alzheimer's disease-like amyloid pathology
}

Maria Teresa Ferretti ${ }^{1}$, Simon Allard ${ }^{1}$, Vanessa Partridge ${ }^{1}$, Adriana Ducatenzeiler ${ }^{1}$ and A Claudio Cuello ${ }^{1,2,3^{*}}$

\begin{abstract}
Background: A growing body of evidence indicates that inflammation is one of the earliest neuropathological events in Alzheimer's disease. Accordingly, we have recently shown the occurrence of an early, pro-inflammatory reaction in the hippocampus of young, three-month-old transgenic McGill-Thy1-APP mice in the absence of amyloid plaques but associated with intracellular accumulation of amyloid beta petide oligomers. The role of such a pro-inflammatory process in the progression of the pathology remained to be elucidated.
\end{abstract}

Methods and results: To clarify this we administered minocycline, a tetracyclic derivative with anti-inflammatory and neuroprotective properties, to young, pre-plaque McGill-Thy1-APP mice for one month. The treatment ended at the age of three months, when the mice were still devoid of plaques. Minocycline treatment corrected the upregulation of inducible nitric oxide synthase and cyclooxygenase-2 observed in young transgenic placebo mice. Furthermore, the down-regulation of inflammatory markers correlated with a reduction in amyloid precursor protein levels and amyloid precursor protein-related products. Beta-site amyloid precursor protein cleaving enzyme 1 activity and levels were found to be up-regulated in transgenic placebo mice, while minocycline treatment restored these levels to normality. The anti-inflammatory and beta-secretase 1 effects could be partly explained by the inhibition of the nuclear factor kappa B pathway.

Conclusions: Our study suggests that the pharmacological modulation of neuroinflammation might represent a promising approach for preventing or delaying the development of Alzheimer's disease neuropathology at its initial, pre-clinical stages. The results open new vistas to the interplay between inflammation and amyloid pathology.

Keywords: Alzheimer, Aß?ß?-oligomers, BACE, iNOS, Microglia, Minocycline, NFkB

\section{Background}

Alzheimer's disease $(\mathrm{AD})$ is a devastating neurodegenerative condition affecting more than 35 million people worldwide [1]. Neuropathological examination of the brains of AD patients reveals intraneuronal neurofibrillary tangles (composed of paired filaments of abnormally phosphorylated tau protein [2]), and massive accumulation of

\footnotetext{
* Correspondence: claudio.cuello@mcgill.ca

'Department of Pharmacology and Therapeutics, McGill University, 3655 Promenade Sir-William-Osler, Room 1210, Montreal, QC H3G 1Y6, Canada Full list of author information is available at the end of the article

extracellular amyloid plaques composed of aggregated amyloid beta peptide $(A \beta)[3]$.

The initiating event for $A \beta$ production is the cleavage of the amyloid precursor protein (APP) by the $\beta$ site APP cleaving enzyme 1 (BACE-1), a neuronal specific aspartyl protease [4]. This event generates a soluble $\mathrm{N}$-terminus exodomain (soluble APP $\beta$ ) liberated into the lumen and a $\beta$-C-terminus fragment ( $\beta$-CTF) bound to the membrane. Gamma secretase cleavage of the membraneanchored $\beta$-CTF releases $A \beta$ peptides of different lengths, including $A \beta 38, A \beta 40$ and $A \beta 42$ [5]. $A \beta 42$ readily aggregates into neurotoxic oligomers and eventually 
forms mature fibrils and plaques [6]. Amyloid plaques in humans and animal models are invariably accompanied by activated astrocytes and microglia with elevated levels of pro-inflammatory products [7].

While $A \beta$ accumulation and aggregation are considered central events in the AD neuropathology, the mechanisms that underlie these processes remain to be elucidated. In particular, the role of neuroinflammation in the progression of the disease is a matter of intense debate. There is increasing awareness that the inflammatory response in neurodegeneration is a highly dynamic process [8]. In $\mathrm{AD}$, most studies have focused on the late, plaque-associated glial activation; this phenomenon has been the object of extensive investigations and it has been well-characterized in the human brain, in several animal models and in in vitro settings [7]. While fibrillar $A \beta$-stimulated microglia are capable of secreting toxic factors in vitro [9], peri-plaque microglia appear to elicit mostly beneficial effects in vivo, limiting plaque growth by phagocytosing $A \beta$ and releasing neurotrophic factors $[10,11]$. In agreement with such observations, prospective clinical trials with anti-inflammatory drugs in patients with AD have shown no effect, or even a worsening of the pathology [12-14]. On the other hand, epidemiological data demonstrated that life-long users of nonsteroidal anti-inflammatory drugs (NSAIDs) develop AD with reduced frequency. This association suggests the existence of a latent pre-clinical inflammatory process which would facilitate the disease progression (for a review, see [15]).

Besides the epidemiological studies, a growing body of evidence in the literature supports the concept that inflammation is an early event in the progression of AD. Microglial activation could be detected in patients with mild cognitive impairment (MCI), which represents the prodromal stage of AD [16-19]. Furthermore, gliosis and up-regulation of IL- $1 \beta$ have been reported in fetal and neonate patients with Down syndrome [20]. Since individuals with Down syndrome invariably develop plaque pathology by mid-age, prenatal and neonatal samples can be considered as pre-plaque conditions.

Taken together, the available evidence strongly indicates that microglial activation occurs early in the progression of the disease. It is very likely that the glial response at the first stages of the neurodegenerative process differs significantly from the well-established periplaque inflammation, and could accelerate the onset of the disease. Unfortunately, direct investigation of microglial activation and its role in pre-clinical stages of $\mathrm{AD}$ is complicated by the fact that it is impossible to predict the conversion of individuals with no cognitive impairment into individuals with $\mathrm{MCI}$ or $\mathrm{AD}$. Therefore, very little is known about the status of microglial activation and its role in the earliest, pre-clinical stages of AD.
In this regard, transgenic ( $\mathrm{Tg}$ ) animal models, which faithfully recapitulate the main hallmarks of the AD-like amyloid pathology, offer the opportunity to investigate events associated with the progression of the disease. It is becoming increasingly clear that $\mathrm{Tg}$ mice with extensive plaque deposition but without neurofibrillary tangles and neuronal loss represent a relatively early stage of the pathology compared to a human brain and are most likely models of early AD and MCI [21]. Accordingly, pre-plaque APP-Tg mice can be valuable tools to elucidate even earlier events preceding plaque deposition.

Using this approach, we have recently described the occurrence of an early, pre-plaque inflammatory response in our newly generated McGill-Thy1-APP mouse Tg model of AD-like amyloid pathology that would mimic the pre-morbid $\mathrm{AD}$. In this Tg model, plaque deposition begins around four to five months of age [22]; however, up-regulation of inflammatory markers and activation and mobilization of microglia can be detected as early as three months of age [23]. Indications of pre-plaque inflammation have also been reported for other models such as APP(V717) [24], R1.40 [25] and 3xTg [26]. However, the role of such early neuroinflammation in the progression of the amyloid pathology had not yet been determined.

To define the role of the early, pro-inflammatory events observed at pre-plaque stages of the AD-like amyloid pathology, we tested the therapeutic effect of minocycline, a tetracyclic derivative with anti-inflammatory properties, in young, pre-plaque McGill-Thy1-APP Tg mice. The treatment lasted one month and ended when the mice were three months old, thus prior to the appearance of the first plaques. This strategy allowed us specifically to investigate the role of inflammation in early, pre-plaque stages of the amyloid pathology, which should correspond to the earliest, pre-clinical stages in the human. We gathered biochemical and morphological evidence indicating that early, pre-plaque neuroinflammation can be blocked by minocycline treatment. The reduction of inflammatory markers was accompanied by reduced activity of BACE- 1 and correction of the nuclear factor-kappa-light chain enhancer of activated B cells (NFkB) pathway.

\section{Materials and methods}

\section{Animals and treatment}

For these studies we used our in-house APP Tg mouse model of AD-like amyloid pathology, coded McGill-Thy1APP [22]. The mice carry the human APP transgene with the Swedish and the Indiana mutations under the control of the murine Thy1.2 promoter. All the animals were two months old when they started the treatment, and were sacrificed at three months of age. Young, pre-plaque twomonth-old Tg mice received minocycline by intraperitoneal injection for one month ( $\operatorname{Tg}$ Mino, $\mathrm{n}=7$ ); control 
groups included vehicle-treated Tg mice (Tg Placebo, $\mathrm{n}=$ 7 ), vehicle-treated non Tg, age-matched littermates (Non Tg Placebo, $\mathrm{n}=8$ ) and non Tg, age-matched littermates treated with minocycline (Non Tg Mino, $\mathrm{n}=8$ ). All the animals received intraperitoneal injections of $200 \mathrm{uL}$ of solution, alternating the injection side, every day for one month. Minocycline hydrochloride was purchased from Sigma-Aldrich Canada (M9511; Oakville, ON, Canada) and a fresh solution of $5 \mathrm{mg} / \mathrm{mL}(10 \mathrm{mM})$ was prepared in filtered PBS and stored at $-80^{\circ} \mathrm{C}$ for one week. Since the $\mathrm{pH}$ of minocycline hydrochloride is acidic ( $\mathrm{pH} 4)$, we corrected it to neutrality by adding sodium hydroxide (as described by [27]). Minocycline-treated animals received a dose of $50 \mathrm{mg} / \mathrm{Kg} /$ day $(200 \mu \mathrm{L}$ of $5 \mathrm{mg} / \mathrm{mL}$ solution equating to $1 \mathrm{mg}$, which, for an average mouse weighing $20 \mathrm{~g}$, corresponds to $50 \mathrm{mg} / \mathrm{Kg}$ ). This dose is similar to previous studies [28] and is expected to result in micromolar concentrations of the drug in the brain [29]. Placebo animals received an equal volume of filtered PBS, $\mathrm{pH}$ 7.4.

The animals were housed in groups of up to four in individually ventilated cages under standard conditions $\left(22^{\circ} \mathrm{C}, 12 \mathrm{~h}\right.$ light-dark cycle) receiving food and water $a d$ libitum. All procedures were approved by the Animal Care Committee of McGill University and followed the guidelines of the Canadian Council on Animal Care. After three weeks of the treatment, one Non Tg Mino mouse had to be euthanized for a swollen intestine and two Tg Mino mice died (no statistical difference was found in the mortality across genotypes, $P=0.59$, chi-squared test). No mice died in the placebo groups. At the end of the treatment the animals (Non Tg Placebo: $\mathrm{n}=8$, six females and two males; Tg Placebo: $\mathrm{n}=7$, five females and two males; Non Tg Mino: $\mathrm{n}=7$, six females and one male; Tg Mino: $\mathrm{n}=5$, two females and three males) were sacrificed by transcardial perfusion and the brains processed for biochemical and immunohistochemical analysis.

\section{Perfusion and tissue preparation technique}

$\mathrm{Tg}$ and Non Tg littermate mice were deeply anesthetized with equithesin (pentobarbital-based, $2.5 \mathrm{~mL} / \mathrm{Kg}$, intraperitoneal injection) and perfused through the heart with icecold saline solution ( $\mathrm{pH}$ 7.4) for 1 minute. The brains were then quickly removed and divided into right and left hemisphere on ice. The cortex, hippocampus and cerebellum were dissected from the left hemisphere, snap-frozen in dry ice and stored at $-80^{\circ} \mathrm{C}$ for biochemical analysis. Cortical samples were used for the determination of inflammatory marker levels and APP-related products, while hippocampi were used for BACE-1 activity assay and BACE, NFkB and inhibitor of $\mathrm{kb}(\mathrm{IkB})$ quantification. The right hemisphere was fixed in $4 \%$ paraformaldehyde in $0.1 \mathrm{M}$ phosphate buffer ( $\mathrm{pH} 7.4$ ) for 24 hours at $4^{\circ} \mathrm{C}$. The tissue was then cut into $40-\mu \mathrm{m}$ thick sections with a freezing sledge microtome (SM 2000R, Leica, Wetzlar,
Germany) and free-floating sections were collected in PBS and processed for immunohistochemistry.

\section{Western blotting Inflammatory markers}

Cortical samples from the left hemisphere were homogenized in $250 \mu \mathrm{L}$ of lysis buffer $(50 \mathrm{mmol} / \mathrm{L}$ Tris- $\mathrm{HCl}, 150$ $\mathrm{mmol} / \mathrm{L}$ sodium chloride, $1 \%$ Nonidet P-40, 0.1\% sodium dodecyl sulfate, $0.1 \%$ deoxycholic acid, $2 \mu \mathrm{g} / \mathrm{mL}$ of aprotinin, $2 \mu \mathrm{g} / \mathrm{mL}$ of leupeptin, $100 \mu \mathrm{g} / \mathrm{mL}$ phenylmethanesulfonyl fluoride, $\mathrm{pH}$ 7.4). The samples were centrifuged at $13,000 \mathrm{rpm}$ for 45 minutes at $4^{\circ} \mathrm{C}$. Following total protein content quantification (Dc-protein assay, Bio-Rad, Hercules, CA, USA), $100 \mu \mathrm{g}$ of protein were separated using $10 \%$ SDS-PAGE and semi-dry transferred to nitrocellulose membranes for subsequent western blotting. Membranes were blocked with $5 \%$ non-fat milk in Tris-buffered saline (TBS) containing $0.1 \%$ Tween 20 (TBS-T) and then incubated with the primary antibody overnight at $4^{\circ} \mathrm{C}$. Primary antibodies used were rabbit polyclonal anti-inducible nitric oxide synthase (iNOS) and IL-1 $\beta$ (both 1:500; Santa Cruz Biotechnology Inc., CA, USA); cyclooxygenase-2 (COX-2; 1:2000; Cayman Chemicals, Ann Arbor, MI, USA); and mouse monoclonal anti $\beta$ III-tubulin (1:40,000; Promega, Madison, WI, USA). Horseradish peroxidase (HRP)-conjugated anti-rabbit and anti-mouse secondary antibodies were purchased from Jackson (Jackson Immunoresearch Laboratories, West Grove, PA, USA). The HRP signal was revealed with a chemiluminescence assay (ECL, GE Healthcare, Amersham, UK) on films. Signal intensity was quantified by densitometry (MCID4 image analysis system, Imaging Research Inc., St. Catherine's, ON, Canada). The levels for each marker were normalized with respect to $\beta$ III-tubulin (neuronal specific) immunoreactivity. All experiments were performed in triplicate.

\section{Tris-tricine western blotting for amyloid precursor protein and amyloid precursor protein-related products}

Total proteins (100 to $250 \mu \mathrm{g}$ ) from the cortical homogenates (prepared as indicated above) were run in pre-cast commercially available 10 to $20 \%$ Tris-tricine gels (Criterion, Bio-Rad Laboratories). The proteins were semi-dry transferred on nitrocellulose (for 6E10 detection) or polyvinylidene fluoride (for pab27576) for 2 hours at $12 \mathrm{~V}$. The membranes were boiled for 5 minutes in PBS, then blocked for 2 hours with milk $10 \%$ and incubated with the specific antibody over night at $4^{\circ} \mathrm{C}$. Antibodies used were monoclonal mouse antibodies 6E10 (1:1000; directed against the residues 1 to 16 of human $A \beta$; from Signet, provided by Covance, Princeton, NJ, USA) and neuron specific $\beta$ III tubulin (1:40,000; Promega); and rabbit polyclonal pab27576 (1:250; directed against the C-terminus of APP; a generous gift from Dr Multhaup, Freie University, Berlin). The quantification was performed as described above; for CTF, the duplet was quantified. For the 
calibration curve, a recombinant CTF (C100 protein purified recombinantly from Escherichia coli) was used (generous gift from Dr Multhaup). The C100 had a C-terminal hexa-His tag and an $\mathrm{N}$-terminal start-methionine. The calibration curve appeared to be linear $\left(\mathrm{r}^{2}=0.99\right)$ in the range between 7 and $0.43 \mathrm{ng}$ per lane.

$\beta$-site APP cleaving enzyme 1, nuclear factor kappaB and inhibitor of $k b$

The hippocampi were briefly sonicated in $100 \mu \mathrm{L}$ of Cell Extraction Buffer (provided with the BACE activity kit, see below), incubated on ice for 15 minutes and centrifuged at $10,000 \mathrm{rpm}$ for 5 minutes at $4^{\circ} \mathrm{C}$. The protein content was quantified as described above and $100 \mu \mathrm{g}$ of total protein was separated using 10\% SDS-PAGE and transferred to polyvinylidene fluoride membrane for subsequent western blotting. Membranes were blocked with 5\% non-fat milk in TBS-T and then incubated with the primary antibody overnight at $4^{\circ} \mathrm{C}$. The primary antibodies used were rabbit polyclonal BACE-1 (PA1-757, 1:250; Thermo Scientific Pierce antibodies, Meridian Road Rockford, IL, USA); NFkB (p65, 1:1000) and IkB (1:2000; both from Santa Cruz Biotechnology Inc.); and actin (1:20,000; Abcam, Cambridge, MA, USA). Band quantification was performed as described above. All experiments were performed in triplicate.

\section{Immunohistochemistry and quantification of ionized} calcium-binding adaptor molecule 1 immunoreactive cells Bright field immunohistochemistry

Free-floating immunohistochemical staining was performed as previously described [30,31] using the rabbit polyclonal primary antibody ionized calcium-binding adaptor molecule 1 (Iba-1; 1:10,000; Wako Chemicals USA, Inc., Richmond, VA, USA). For the detection, a biotinylated goat anti-rabbit secondary antibody was applied followed by amplification with the avidin-biotin complex (ABC elite kit, both from Vector Laboratories Inc., Burlingame, California, USA). All stainings were developed with $0.06 \%$ 3,3'-diaminobenzidine (Sigma-Aldrich Canada) and $0.01 \%$ hydrogen peroxide.

Quantification of ionized calcium-binding adaptor molecule 1-immunoreactive cell soma size and density

The staining and the quantification of Iba- 1 immunoreactive (ir) cells were performed according to published protocols [23]. All the stainings were performed simultaneously. Three sections per animal were chosen in the area corresponding to bregma -2.9 [32], stained with Iba1 and mounted on gelatinated slides, after which the slides were coded. Digital images were acquired on an Axioplan 2 Imaging microscope (Zeiss, Toronto, ON, Canada), equipped with an AxioCam HRc digital camera (Zeiss), using AxioVision 4 Imaging program (Zeiss). The micrographs were taken with a $63 \times$ Zeiss plan-Apochromat oil immersion objective in the CA1 area of the hippocampus (eight micrographs per section, three sections per animal for a total of 24 micrographs per animal,) and, as a control, four micrographs were taken in the lateral posterior thalamic nucleus (total of 12 micrographs per animal). The images were imported into the MCID 5 Image Analysis Software (Imaging Research Inc.) as tagged image file format files and transformed (with the 'target accent' function) to allow optimal detection by the program. Cell bodies of all the cells in the focal plane of each micrograph were manually outlined by a blinded observer before target size, number of target elements, intensity and form factor were measured in an automatic fashion. After quantification, the slides were decoded and the data analyzed. The density data are expressed as the number of Iba1-ir cells per field (38.206 $\mu \mathrm{m}^{2}$ ). MTF was blind to the nature of the material at all stages of the quantification.

\section{Enzyme-linked immunosorbent assay for human amyloid beta peptide}

Human $A \beta 40$ and $A \beta 42$ levels were quantified from cortical homogenates using a commercially available ELISA kit (Invitrogen, Carlsbad, CA, USA; distributed by Medicorp, Montreal, Canada). Each sample was mixed in an equal volume of guanidine- $\mathrm{HCl}$ (to a final concentration of $5 \mathrm{M}$ guanidine) and incubated for 3 hours at room temperature. The resulting samples were further diluted 1:10 in the provided dilution buffer (to a final concentration of 0.5 $M$ guanidine) and tested in duplicate. The amount of $A \beta$ was extrapolated from a calibration curve of synthetic human $A \beta 40$ and $A \beta 42$ using the curve fitting function of Graph-Pad Prism 5 software (La Jolla, CA, USA). The calibration curve was prepared according to the manufacturer's instructions in the presence of $0.5 \mathrm{M}$ guanidine to ensure comparability with experimental samples. The data were normalized on total micrograms of protein content per sample. Controls included: omission of samples (background), chromogenic substrate alone (blank) and Non Tg samples. No signal was detectable in Non Tg samples (data not shown).

\section{$\beta$-site APP cleaving enzyme 1 activity}

We used two commercially available kits for the measurement of BACE-1 enzymatic activity from the biological samples (R\&D, Minneapolis, MN, USA and Abcam, Cambridge, MA, USA). The assay was conducted according to manufacturer's instructions. Briefly, hippocampal samples (see above for preparation details) were diluted to a final concentration of $2.5 \mu \mathrm{g} / 50 \mu \mathrm{L}$. From the resultant samples, $2.5 \mu \mathrm{g}$ of total protein were loaded into a black 96-well microplate and the fluorogenic substrate was added in the dark. The substrate is conjugated to the EDANS and DABCYL reporter molecules. Cleavage of the peptide by $\beta$-secretase separates EDANS and DABCYL, allowing for the release of a fluorescent signal. The reaction was incubated at $37^{\circ} \mathrm{C}$ for one hour in the dark, and the signal was 
measured using a Fluostar Optima (BMG Labtech $\mathrm{GmbH}$, Ortenberg, Germany) with $355 \mathrm{~nm}$ excitation and $520 \mathrm{~nm}$ emission wavelengths. Each sample was run in duplicate; the assay was repeated twice and results from the two experiments were pooled after normalization on Non $\mathrm{Tg}$ Placebo values. Negative controls included: omission of the fluorogenic peptide (background fluorescence of the tissue), omission of the sample (blank) and addition of BACE-1 inhibitor to the samples (provided by the kit). We ran $2.5 \mu \mathrm{g}$ of recombinant human peptide (rhBACE-1: $R \& D)$ as a positive control.

\section{Postnatal day 7 samples for $\beta$-site APP cleaving enzyme 1 western blot}

Two pups from postnatal day 7 were sacrificed and the brains carefully removed; one brain was immediately homogenized as described above for regular western blotting, while the cortex of the second brain was used to establish a mixed glial culture according to standard protocols with minor modifications [33]. Briefly, the cells were disaggregated using papain (Worthington, Lakewood, NJ, USA) and mild mechanical stress with a polished Pasteur pipette. The cells were then re-suspended in DMEM containing 10\% FBS and penicillinstreptomycin, and cultured in a $10-\mathrm{cm}$ petri dish. The medium was changed every three to four days and after two weeks the cells were collected by scraping on ice, then sonicated and processed for western blotting.

\section{Data analysis}

All data were analyzed using the Graph-Pad Prism 5 software (La Jolla). Multiple groups' comparison was done by one-way analysis of variance (ANOVA) followed by Tukey post-hoc test. Kruskal-Wallis was used for non-normally distributed data. The interaction between the genotype and effect of the drug was studied using two-way ANOVA. Correlation studies were done using the Spearman's test for non-normally distributed data. Significance was set at $P<0.05$. All data are presented as mean \pm standard error of the mean.

\section{Results}

Minocycline corrects neuroinflammation in pre-plaque McGill-Thy1-APP Tg mice

We first assessed the ability of minocycline to reduce the central nervous system (CNS) pro-inflammatory process in young, pre-plaque $\mathrm{Tg}$ mice by measuring levels of iNOS, COX-2 and IL-1 $\beta$ via western blotting (Figure 1AC). Confirming and further expanding our previous sets of experiments [23], we found that iNOS and COX-2 were significantly up-regulated in cortical homogenates from Tg mice compared to Non Tg littermates (Figure 1A, B, $P<0.05)$. IL-1 $\beta$ showed a trend towards up-regulation which did not reach significance (Figure 1C). Minocycline treatment was able to inhibit neuroinflammation, as the levels of iNOS, IL- $1 \beta$ and COX-2 of Tg mice treated were significantly different from Tg Placebo $(P<0.01)$ but not significantly different from Non $\mathrm{Tg}$ controls.

Minocycline treatment did not significantly alter the levels of these markers in Non Tg animals. The following fold increases compared to Non Tg Placebo were observed in Non Tg Mino: iNOS, $1.49 \pm 0.19$; IL- $1 \beta$, $0.99 \pm 0.04$; COX-2, $1.31 \pm 0.15$. None of these reached significance $(P=0.08,0.95$ and 0.31 , respectively; Student's $t$-test), even though a trend was observed for the iNOS levels.

To confirm the biochemical data, we used a morphological approach to study the activation state of microglial cells. Iba-1, a structural marker for microglia [34], was used to stain brain sections from $\mathrm{Tg}$ and Non $\mathrm{Tg}$ animals. As expected, most microglial cells in Non Tg Placebo mice displayed a resting morphology, with a small soma size and symmetrical, fine arborization of the processes (Figure 1E). As previously reported, we observed an altered morphology of the microglial cells from the hippocampus of Tg Placebo animals. The cells displayed an enlarged soma size, with notable polarization and thickening of the processes, all indicative of microglial activation. In contrast, microglial cells from minocycline-treated $\mathrm{Tg}$ animals (Tg Mino) displayed a small, roundish soma, similar to Non Tg Placebo. Interestingly, we noticed an increase in the complexity of microglia ramification following minocycline treatment in $\mathrm{Tg}$ animals; the number of processes emanating from the cells appeared to be elevated and they were often thick and decorated by spines. Microglial soma size and density was measured with the assistance of the MCID 5 Image Analysis System, according to published protocols [23]. Reinforcing our biochemical results, we observed a significant down-regulation of microglial cells size in the hippocampus of $\mathrm{Tg}$ animals treated with minocycline (Figure 1G, $P<0.05$ ) indicative of a reduced activation or reversal to a resting state. No differences in the density of microglial cells were observed, suggesting that the effect of minocycline was not mediated by a reduction in microglial proliferation.

No significant differences were found between the microglial soma size in Non Tg Placebo $\left(38.86 \mu \mathrm{m}^{2} \pm\right.$ $0.37)$ and Non Tg Mino $\left(39.64 \mu \mathrm{m}^{2} \pm 1.16\right)$.

The analysis of microglial morphology was performed in the lateral posterior thalamic nucleus in the same sections (Figure 1F) as a control area which is spared by the amyloid pathology at this age [22]. In agreement with previous reports [35], we noticed that microglial cells in this area were smaller, less ramified and less dense than in the hippocampus. The analysis of microglial cells soma size and density in the thalamus revealed no differences between 
A
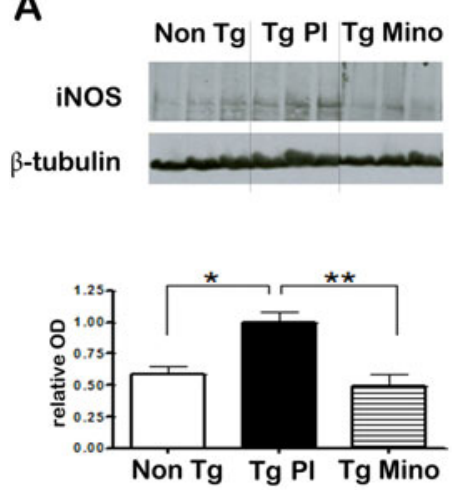

D

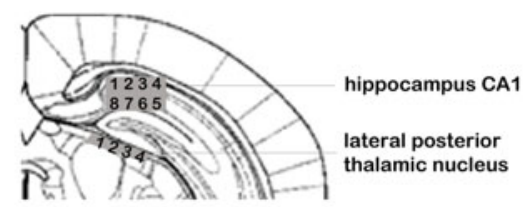

E

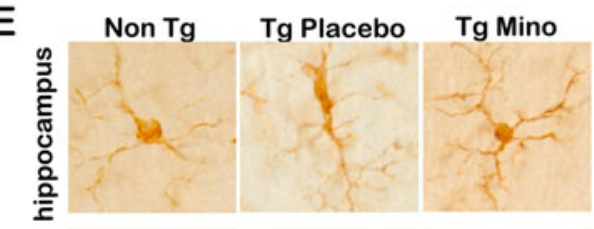

F

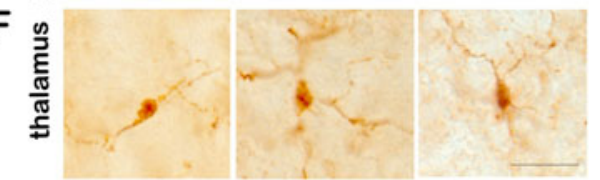

B
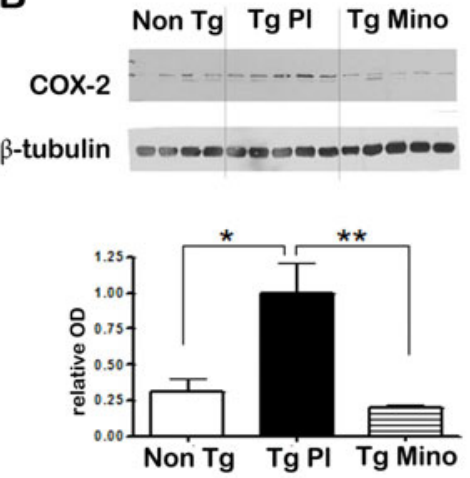

G
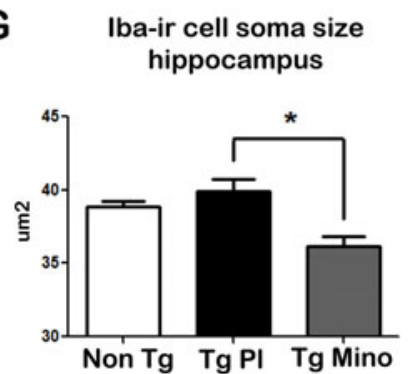

H

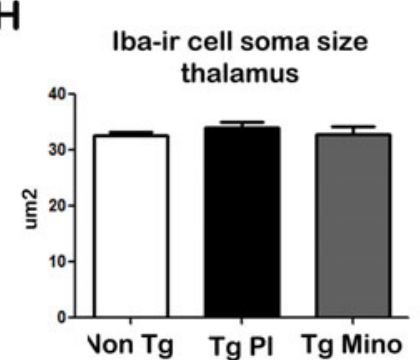

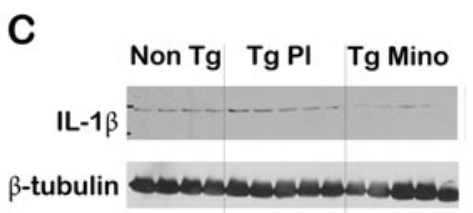

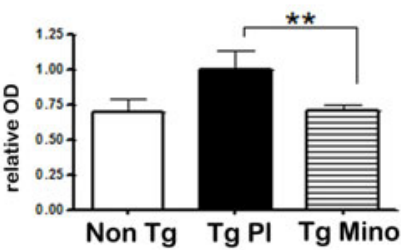

Figure 1 Minocycline corrects neuroinflammation in young, pre-plaque Tg mice. (A-C) Representative western blots for iNOS, COX-2 and IL-1 $\beta$ (typical markers of microglial and neuronal activation) in control, Non Tg Placebo mice (Non Tg), $\mathrm{Tg}$ Placebo mice (Tg PI) and Tg mice treated with minocycline (Tg Mino). Note the significant up-regulation of iNOS and COX-2 in Tg PI compared to Non Tg. Minocycline restored iNOS and COX-2 to levels similar to those of Non Tg, and significantly reduced the levels of IL-1 $\beta\left(^{*} P<0.05\right.$, ** $P<0.01$, one-way ANOVA with Tukey post-hoc test). See main text for the values of Non Tg treated with minocycline. (D) Schematic illustrating the sampling of images in the CA1 area of the hippocampus and from the lateral posterior thalamic nucleus as utilized for the morphological study represented in E-G. (E) Representative micrographs illustrating the ir of Iba-1 in microglial cells in the hippocampus of the Non Tg, Tg Pl and Tg Mino mice. Note the altered morphology of the microglial cells in Tg PI compared to Non Tg. In Tg PI mice, we observed an enlargement of the soma size, polarization and thickening of the microglial processes, which are classical indicators of microglial activation. Minocycline treatment resulted in correction of microglial soma size (note the small, roundish morphology), with some residual thickening of processes and increase in spiny processes. (F) Representative micrographs illustrating the ir of Iba-1 in microglial cells in the lateral posterior thalamic nucleus of the Non Tg, Tg $\mathrm{PI}$ and Tg Mino. The cells were notably smaller and less ramified than in the hippocampus, but no differences in the morphology could be observed between experimental groups. Scale bar for E and F: $20 \mu \mathrm{m}$. (G,H) Quantification of cell soma size and density of microglial cells from hippocampus (G) and thalamus $(\mathrm{H})$ in Non $\mathrm{Tg}, \mathrm{Tg} \mathrm{Pl}$ and $\mathrm{Tg}$ Mino. Note that minocycline treatment resulted in significant reduction of microglial cells soma size compared to $\mathrm{Tg} P \mathrm{Pl}$ in the hippocampus (G). No significant differences were observed in the soma size of cells in the thalamus $(H)$. As previously reported [23], no significant changes in microglial cell density were observed between Non Tg and Tg. This pattern was not altered across experimental groups in any area. ( $P<0.05$, one-way ANOVA followed by Tukey post-hoc test). Non Tg: Non Tg Placebo mice; Tg Mino: Tg mice treated with minocycline; Tg PI: Tg Placebo. 
groups (Figure 1H). This result indicated that the effect of minocycline was specific to the hippocampus, an area burdened with intracellular $\mathrm{A} \beta$-ir material.

\section{Minocycline treatment affects amyloid precursor protein metabolism}

Next, we investigated the effects of the anti-inflammatory treatment on APP metabolism and A $\beta$ levels (Figure 2). For these studies we used cortical homogenates from $\mathrm{Tg}$ Placebo and Tg Mino.

We first applied the commercially available monoclonal antibody 6E10, which recognizes residues 1 to 16 of human $A \beta$. This western blot analysis revealed several ir bands in Tg Placebo animals between $10 \mathrm{kDa}$ and $50 \mathrm{kDa}$. These bands did not appear in the Non Tg homogenates, and are likely to be oligomeric forms of $A \beta$. Minocycline treatment resulted in the clearance of most of the 6E10-ir bands; in particular, a strong (-70\%), significant down-regulation of a $12-\mathrm{kDa}$ band (Figure $2 \mathrm{~A}$ and $2 \mathrm{~B}$ ) was observed. We noticed that the levels of the $12-\mathrm{kDa}$ band strongly correlated with the levels of iNOS across samples (Figure 2C, $r=0.81, \mathrm{P}=0.004$, Spearman's correlation analysis). In these experimental cohorts, Tg Placebo mice displayed the highest values for both $12 \mathrm{kDa}-6 \mathrm{E} 10$ and iNOS, while all but one of the Tg mice treated with minocycline displayed reduced levels of both markers. These results would suggest a link between APP metabolism and the inflammation staging.

The $12-\mathrm{kDa}$ band could not be definitively identified. In fact, the $6 \mathrm{E} 10$ antibody is directed against the $\mathrm{N}$-terminus residues of $A \beta$ and therefore can recognize both $\beta$-CTF fragments of APP (that migrate around $12 \mathrm{kDa}$ ) and A $\beta$ species (such as $A \beta$-trimers). To elucidate the nature of the $12-\mathrm{kDa}$ band, we performed additional analysis on the homogenates that enabled us to specifically quantify the amount of CTF fragments and human $A \beta$.

To detect CTF fragments without cross-reactivity with $A \beta$, we used a specific antibody directed against the $C$-terminus of the APP holoprotein pab27576 (generous gift from Dr Multhaup, Freie University, Berlin [36]). This serum recognizes full-length APP (flAPP, which appeared at $100 \mathrm{kDa}$ ) and CTFs (which migrated around $12 \mathrm{kDa}$ ). In order to quantify the levels of CTF in the sample, in the same gels we included a calibration curve of recombinant CTF (Figure 2D). After this analysis, we quantified the levels of flAPP and CTF fragments (Figure 2E). We observed a significant down-regulation of flAPP relative levels (Figure 2E, $P<0.01$ ) in Tg Mino animals compared to Tg Placebo. The down-regulation of flAPP was confirmed using other APP-specific antibodies such as 6E10 and $22 \mathrm{C} 11$ (data not shown).

Extrapolation of the levels of CTF in the brain homogenates from the calibration curve revealed that $\mathrm{Tg}$ Placebo animals had $10.13 \pm 3.50 \mathrm{ng}$ of CTF per milligram of total protein. In the Tg Mino group, CTF fragments (both relative and absolute levels) appeared reduced $(7.27 \pm 1.34 \mathrm{ng} /$ $\mathrm{mg}$ ) but such reduction did not reach significance. Importantly, the decrease in CTF following minocycline treatment was not completely explained by the reduction in APP levels. In fact, when we normalized the CTF levels on flAPP levels, the trend towards a reduction was still present (Figure 2E, ratio CTF/flAPP). These results suggested that the $12-\mathrm{kDa}$ band recognized by $6 \mathrm{E} 10$ was not exclusively constituted by CTF, as the values detected by the two antibodies were not perfectly correspondent. We therefore sought to quantify $A \beta$ levels in the same samples.

To obtain a direct quantitative measurement of the $A \beta$ levels we performed an ELISA analysis of human $A \beta 40$ and $A \beta 42$. The study revealed the presence of $160.9 \pm 24.37 \mathrm{pg} / \mathrm{mg}$ total protein of $\mathrm{A} \beta 42$ and $38.28 \pm$ $4.25 \mathrm{pg} / \mathrm{mg}$ total protein of $\mathrm{A} \beta 40$ in Tg Placebo animals. After minocycline treatment we measured $109.0 \pm 13.43$ $\mathrm{pg} / \mathrm{mg}$ total protein of $\mathrm{A} \beta 42$ and $28.76 \pm 2.42 \mathrm{pg} / \mathrm{mg}$ of $\mathrm{A} \beta 40$. Though a strong trend was observed towards reduction $(P=0.08$ and 0.09 , respectively), this did not reach significance (Figure $2 \mathrm{~F}$ ).

We then calculated the ratio between $A \beta$ ( $\mathrm{pg} / \mathrm{mg}$ total protein) and CTF (ng/mg total protein) in each sample: this analysis revealed that in the Tg Placebo animals there were $24.29 \pm 6.43 \mathrm{pg}$ of $\mathrm{A} \beta 42$ and $6.76 \pm 2.15 \mathrm{pg}$ of $\mathrm{A} \beta 40$ per each nanogram of CTF. A trend towards a decrease in animals treated with minocycline was found $(15.14 \pm 3.08$ $\mathrm{pg}$ of $\mathrm{A} \beta 42$ and $4.36 \pm 0.58 \mathrm{pg}$ of $A \beta 40$ per each nanogram of CTF), suggesting fewer molecules of $A \beta$ per molecule of CTF following minocycline treatment (Figure 2G).

\section{Minocycline inhibits $\beta$-site APP cleaving enzyme 1 activity in young, pre-plaque $\mathrm{Tg}$ mice}

The strong reduction of the $12-\mathrm{kDa}$ band immunoreactive with $6 \mathrm{E} 10$ and the altered CTF/flAPP ratio observed after minocycline treatment would indicate that the $\beta$ cleavage of APP could be affected by the anti-inflammatory drug. Therefore, we proceeded to measure BACE- 1 activity in the hippocampal samples, using a well-characterized fluorometric assay (Figure 3A and 3B). This kit allowed specific and robust detection of BACE-1 from brain homogenates; the fluorescent signal detected in brain homogenates was seven times higher that background, and was reduced to background levels by co-incubation with the kit BACE inhibitor (Figure 3B).

With this approach we found that $\mathrm{Tg}$ animals displayed significantly increased BACE-1 activity compared to Non Tg $(P<0.001)$. Supporting our biochemical findings on APP processing, we found that minocycline was able to reduce BACE-1 activity in Tg animals, and blunted it to levels that were similar to Non $\mathrm{Tg}(P<0.05 \mathrm{Tg}$ placebo versus Tg Mino). On the other hand, Non Tg animals 
A

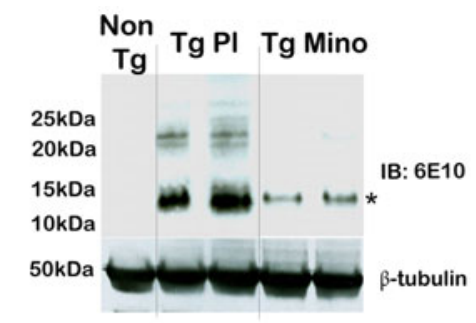

D

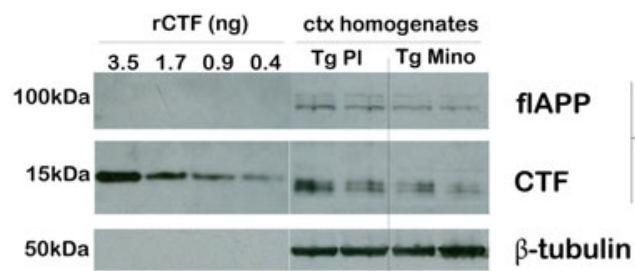

IB: pab 27576

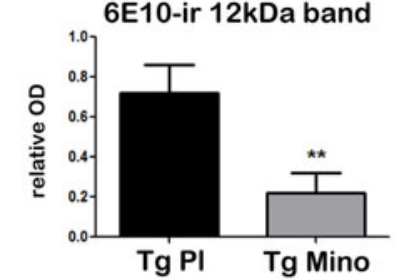

$\mathbf{F}$

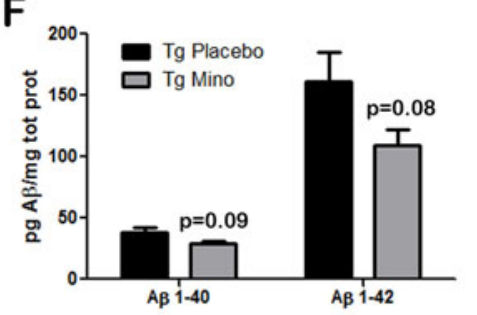

E
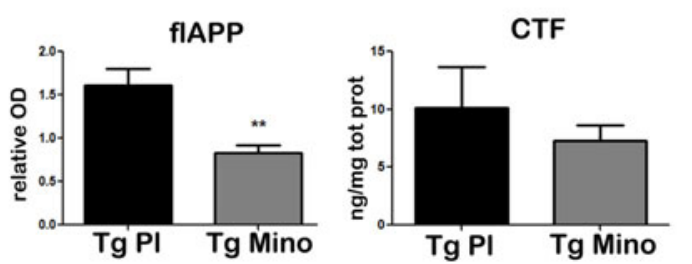
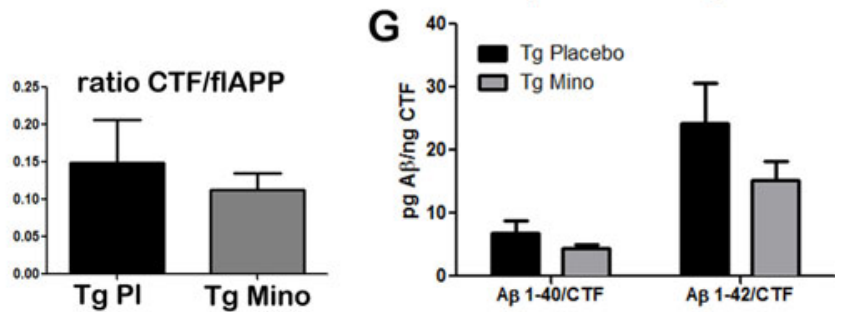

Figure 2 Minocycline effects on amyloid precursor protein metabolism. Cortical brain homogenates from Tg animals treated with vehicle ( $\mathrm{Tg}$ Pl) or minocycline (Tg Mino) were subjected to western blotting and ELISA to determine the levels of A 3 species, full-length APP (fIAPP) and CTF. (A) Representative western blot of cortical homogenates from Tg animals treated with vehicle or with minocycline, using 6E10 antibody. Note the strong down-regulation of the approximately $12-\mathrm{kDa}$ ir band (indicated with an asterisk) which likely represents a mixture of $\beta$-CTF of APP and A $\beta$ trimers. (B) Densitometric analysis of the 12-kDa band detected with 6 E10. Values were normalized on neuronal specific $\beta$-tubulin. Minocycline-treated animals showed significantly lower levels compared with placebo (**P $<0.01$, Student's $t$-test). (C) Correlation analysis of the levels of the 12-kDa band ir to 6 E10 and the levels of iNOS per sample. The correlation was found to be highly significant $(r=0.81 ; P=0.004$, Spearman's correlation), where Tg Placebo animals (black dots) had the highest levels of 6E10-ir and iNOS, while Tg Mino (yellow dots) mice displayed reduced levels of ir with $6 \mathrm{E} 10$ and lower levels of iNOS. (D) Representative western blots of cortical (ctx) homogenates from placebo and minocycline-treated animals using the pab27576 antibody. This antibody recognizes an epitope on the C-terminus of APP and therefore detects two prominent bands in the blots: a high molecular weight band (about $100 \mathrm{kDa}$ ), corresponding to flAPP and a faster band (approximately $12 \mathrm{kDa}$ ) corresponded to the CTF fragments. A calibration curve using known amounts of recombinant C100 was run in the same gel for quantification purposes (the recombinant peptide ran slightly slower due to the presence of a C-terminal hexa-His tag). (E) Quantification of flAPP and CTF levels in cortical homogenates from Tg Placebo and Tg-treated animals. FIAPP relative optical density values were normalized on neuronal specific $\beta$-tubulin. Note the significant down-regulation of flAPP ( ${ }^{* *} P<0.01$, Student's $t$-test) in Tg Mino compared with Tg Placebo. CTF absolute levels were extrapolated from the calibration curve of recombinant CTF. There was a non-significant trend towards reduction following minocycline treatment. Normalization of the relative optical density of CTF over the relative optical density of fIAPP confirmed a non-significant trend towards a reduction (ratio CTF/fIAPP). All data were analyzed with Student's t-test. (F) Quantification of human $A \beta$ levels in cortical homogenates from Tg Placebo and Tg Mino using ELISA. The treatment reduced both A $\beta 40$ and A 342 , but the effect did not reach significance ( $P=0.09$ and 0.08 , respectively, Student's $t$-test; see main text for exact values). (G) The ratios between $A \beta$ (pg/mg total protein) and CTF ( $\mathrm{ng} / \mathrm{mg}$ total protein) were calculated per sample and compared across groups. We observed $24.29 \pm 6.43 \mathrm{pg}$ of A $\mathrm{A} 42 \mathrm{and}$ $15.14 \pm 3.08 \mathrm{pg}$ of AB40 per each nanogram of CTF. Minocycline treatment resulted in a reduction of the ratio (which did not reach significance), suggesting that less $A \beta$ was produced per CTF molecule after the treatment with minocycline.

receiving minocycline also displayed up-regulation of BACE-1 activity. A two-way ANOVA revealed that there was a strong interaction between the genotype and the treatment $(P<0.001)$, suggesting that minocycline exerted differential effects according to the genotype.
We used western blotting to quantify BACE-1 levels in the same samples to assess whether the effect observed was due to a pure enzymatic inhibition or to reduction in the protein content (Figure 3D). Even though this assay appeared to be less sensitive than the enzymatic 
A

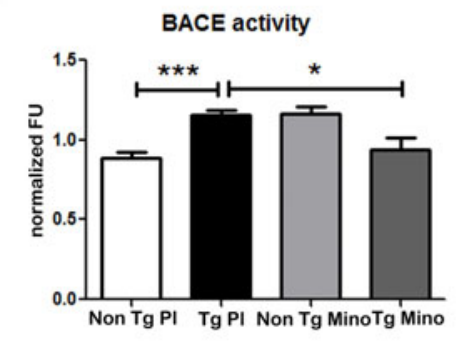

B

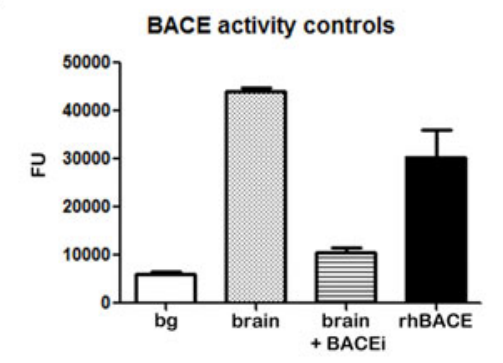

E

C

D

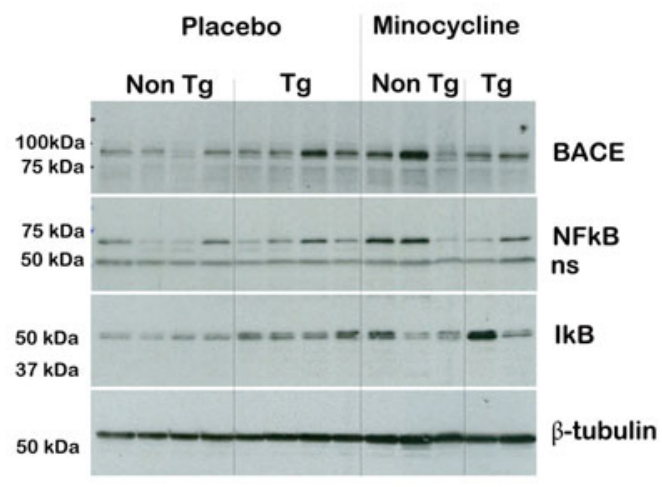

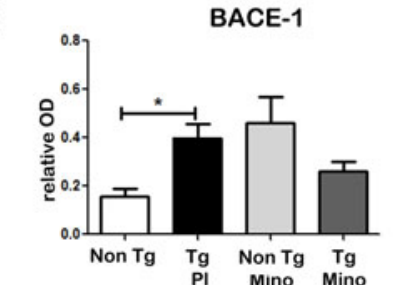

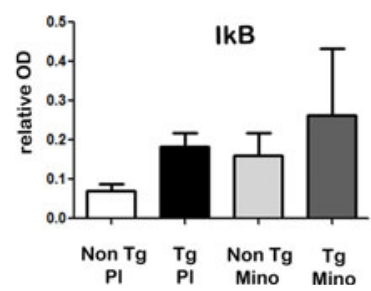

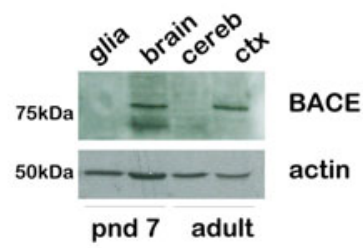
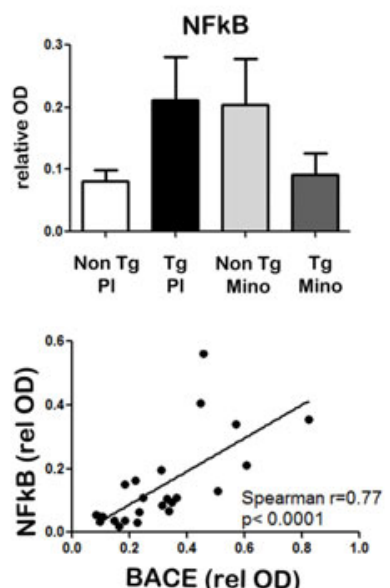

Figure 3 Minocycline inhibits $\beta$-site APP cleaving enzyme 1 in young, pre-plaque Tg mice. (A) BACE-1 activity was quantified from hippocampal homogenates using a well-characterized fluorometric assay. Fluorescent units (FU) data were normalized on Non Tg Placebo values. Note the significant up-regulation of BACE-1 activity in Tg Placebo compared to Non Tg Placebo (*** $<0.001)$, which was corrected following minocycline treatment ( ${ }^{*} P<0.05$ compared to Tg Placebo). (B) Specificity of the BACE-1 fluorometric assay: note how the fluorescent units detected from brain homogenates (of a Non Tg Placebo animal) are seven times higher than the background (bg). The signal was completely abolished by co-incubation with a specific BACE inhibitor (BACEi), and was in the range of activity of a recombinant human BACE protein $($ rhBACE, $2.5 \mu \mathrm{g}$ ). All the data were analyzed with one-way ANOVA followed by Tukey post-hoc test. (C) Specificity of the polyclonal BACE-1 antibody used for western blotting: the specific band (close to $75 \mathrm{kDa}$ ) appeared in brain extracts from post natal day 7 (pnd 7) and from adult cortex (ctx), while it was hardly detectable in cerebellum (cereb) sample and was not detectable in a glial preparation from pups. (D) Representative western blots of BACE-1, NFkB and IkB from the same hippocampal samples used for the enzymatic assay (ns = non-specific band recognized by the polyclonal antibody directed against NFkB). (E) Quantification data of BACE-1, NFkB and IkB from hippocampal homogenates. Band intensity was quantified via densitometry and the values were normalized on the neuronal specific- $\beta$-tubulin content. Note the significant up-regulation of BACE-1 levels in Tg Placebo, which was corrected by the minocycline treatment $(P<0.05)$. The levels of NFkB and BACE-1 in each sample strongly correlated $(P<0.001$, Spearman's correlation analysis). Given the not-normal distribution of the data, the values were analyzed with Kruskal-Wallis test and Spearman's correlation analysis. BACEi: BACE inhibitor; bg; background; cereb: cerebellum; ctx: cortex; pnd: postnatal day; rhBACE: recombinant human BACE.

activity assay, we found a significant up-regulation of BACE-1 protein levels in Tg animals compared to Non Tg (Figure 3E, $P<0.05)$. Minocycline-treated animals had intermediate levels of BACE-1, which were not significantly different from the Tg Placebo nor from the Non Tg levels. Confirming our activity data, Non Tg treated with minocycline displayed elevated levels of BACE-1 (interaction between genotype and treatment: $P$ $<0.01$, two-way ANOVA). The band observed was most likely specific, as it did not appear in naive glial cultures from mice pups and was barely detectable in cerebellum (Figure 3C).
Taken together, these results demonstrated that $\mathrm{Tg}$ animals, even prior to plaque deposition, showed increased levels and activity of BACE-1. Such up-regulation is likely to be related to an inflammatory process, as minocycline could significantly reduce BACE-1 activity and corrected BACE-1 levels.

BACE-1 and many inflammatory mediators such as iNOS, COX- 2 and IL- $1 \beta$ are known to be under the transcriptional control of NFkB $[37,38]$. The active form of human NFkB is a dimer composed of the two DNA binding subunits $\mathrm{p} 50$ and p65. These genes are constitutively expressed in both glia and neurons and their 
mRNA levels are further increased in response to inflammatory signals. Dimers are normally in an inactive form, sequestered in the cytoplasm by the NFkB inhibitor, IkB (for a review, see [38]). Activation by inflammatory stimuli results in phosphorylation and degradation of IkB, translocation of NFkB into the nucleus and expression of target genes. Target genes include inflammatory cytokines, chemokines, acute phase proteins and immune receptors [37]; interestingly, IkB gene also contains NFkB binding sites [39]. We therefore proceeded to measure NFkB (p65) and IkB in the hippocampal samples (Figure 3D).

Consistent with the notion of a pro-inflammatory condition in pre-plaque McGill-Thy1-APP mice, we observed elevated levels of NFkB and IkB in the Tg Placebo animals compared with Non Tg Placebo. Treatment with minocycline in Tg animals resulted in lower levels of NFkB and higher levels of IkB. On the other hand, minocycline-treated Non Tg mice showed increased NFkB and IkB levels. None of these changes reached significance due to high variability, but we found a very strong correlation between BACE-1 levels and NFkB levels (Figure 3E, $P<0.001$, Spearman's correlation analysis). These findings suggested that BACE-1 levels might be under the direct or indirect control of NFkB in vivo.

\section{Discussion}

\section{Experimental design and novelty of the study}

In the present studies, we aimed to elucidate the interaction between activated glia and neurons in the earliest stages of the AD pathology. Several reports in the field have documented the effect of anti-inflammatory treatments with NSAIDs in Tg models of AD-like pathology [40-42]. However, these studies were designed to assess the effect of treatment on plaque pathology, and the animals were sacrificed after plaque onset. Our approach differed from previous reports in that we wanted to clarify the role of inflammation in the early, pre-plaque stages of the pathology, which likely mimic the earliest, pre-clinical stages in AD.

This is a matter of high clinical relevance, as the available data in humans suggest a differential role of inflammation in early versus late stages of the disease. The contribution of the inflammatory process in disease onset has been highlighted by epidemiological, retrospective studies indicating a lower incidence of $A D$ in populations receiving long-term treatment with NSAIDs [43-46]. In contrast, prospective trials applying NSAIDs to patients clinically diagnosed with $\mathrm{AD}$ have failed to reverse or slow down the disease, often worsening it [12-14]. Taken together, the clinical evidence is consistent with the concept that inflammation would contribute to and accelerate the AD neuropathology in its early pre-clinical stages, while it would be neutral or even beneficial in later, clinical stages. It is important to note that this hypothesis has been supported by the recent extended results from an AD anti-inflammatory preventive trial (ADAPT). The study had to be halted after only two years for safety concerns [47]; at that point in time, no beneficial effects were observed with the anti-inflammatory treatment [48]. However, the follow-up results indicated that the naproxen treatment outcome critically depended on the stage of the pathology at the moment of enrolment in the trial $[49,50]$. In this prospective study, in fact, an increased risk of $\mathrm{AD}$ onset was detected in patients who displayed some cognitive impairment (but no dementia) when they entered into the study. Such a cohort would likely represent patients closer to the disease onset. On the other hand, asymptomatic individuals treated with NSAIDs had a reduced AD incidence [49]. The concept of a differential role of inflammation at early versus late stages of the disease has been suggested for other neurodegenerative conditions, such as amyotrophic lateral sclerosis [51], and it might very well be related to the differential subsets of monocytic cells involved [8]. Therefore, the temporal window in which anti-inflammatory treatment can be beneficial and the mechanism involved in such a beneficial effect need to be further studied. We propose that pre-plaque Tg mice can be a valuable model for this type of investigation.

\section{Early microglial activation and its inhibition with minocycline}

In agreement with our previous observations [23], we gathered biochemical (Figure 1A-C) and morphological (Figure 1D-H) evidence indicating the presence of microglial activation in the cerebral cortex and hippocampus at pre-plaque stages in the transgenic mouse model McGill-Thy1-APP.

To investigate the pathological participation of such proinflammatory process in the AD-like amyloid pathology, we chose to administer the tetracyclic derivative minocycline. In addition to its antimicrobial activities, this drug easily crosses the blood-brain barrier and has been shown to be beneficial in several CNS neuropathological conditions and in neurodegeneration [52]. Minocycline appears to exert its action through a plethora of mechanisms, including inhibition of key inflammatory enzymes (such as iNOS, matrix metalloprotease 9 and 5-lipoxygenase), blocking caspase-dependent and independent apoptosis and demonstrating anti-oxidant effects (for a review, see [53]).

Previous reports have studied the effect of minocycline on the full-blown amyloid pathology in APP Tg mice [28,54-56]. Overall, the drug appeared to reduce neuroinflammation and the behavioral deficits observed in $\mathrm{Tg}$ mice. However, in all the previous reports, the animals were sacrificed after plaque onset and the effect on preplaque pathology was not documented. Our study 
therefore represents the first report of the effect of minocycline on early, pre-plaque stages of AD-like amyloid pathology in Tg mice.

As expected, minocycline was indeed effective in reducing inflammation, as COX-2, iNOS and IL- $1 \beta$ levels were all found to be down-regulated in $\mathrm{Tg}$ animals treated with minocycline compared to placebo (Figure 1AC). After minocycline treatment, the microglial soma size of hippocampal cells appeared to be significantly reduced (Figure 1E and $1 \mathrm{G}$ ), along with an increase in the complexity of microglial arborization (as illustrated in the representative micrograph in Figure 1E). Both biochemical and morphological findings suggested decreased pro-inflammatory activity. Given the wellknown complexity of the microglial phenotype [57], it is possible that minocycline exerted its effect by switching the microglial cells to a more neuroprotective, M2-like phenotype. Further studies will be required to pinpoint the features of microglia in response to minocycline treatment, using alternative markers such as CD45 or arginase-1 [58-60]. Interestingly, the anti-inflammatory effect of minocycline was specific to the hippocampus and the cortex, a region burdened with intracellular $\mathrm{A} \beta$ oligomers [22]. In fact, microglial cells of the thalamus, an area largely devoid of $A \beta$ material at this early age, did not appear to be affected by the treatment (Figure $1 \mathrm{~F}$ and $1 \mathrm{H}$ ). This result indicates that minocycline specifically interfered with a pathological inflammatory process dependent on intracellular $A \beta$ accumulation.

\section{Minocycline effects on the amyloid pathology}

Having assessed the ability of minocycline to inhibit the pre-plaque inflammatory process, we set ourselves to study the consequences of such anti-inflammatory treatment on the intracellular, pre-plaque phase of the amyloid pathology.

In our study, as opposed to previous reports of minocycline in AD models, the treatment was started and finished when the animals were devoid of plaques. Therefore, instead of plaque number, we focused our investigation on the cerebral levels of APP, APP-related products and soluble $A \beta$ following minocycline treatment. Soluble levels of $A \beta$ are particularly important indicators of the disease state, as they were shown to correlate with the degree of dementia in AD patients [61]. On the other hand, it is well established that the amyloid plaque burden does not correlate with the severity of the disease [62,63].

In this regard we first noticed that, at this early time point, inhibition of inflammation was associated with the down-regulation of APP (Figure 2). While the cellular mechanisms for such an effect remain to be determined, there is evidence in the literature that inflammatory mediators can modulate APP synthesis. IL- $1 \beta$, for instance, was shown to induce APP synthesis in neurons $[64,65]$. The decrease in flAPP could therefore be a consequence of reduced IL- $1 \beta$ levels.

Besides the down-regulation of flAPP, the most significant effect we observed was the reduction of a $12-\mathrm{kDa}$ band recognized with the monoclonal antibody $6 \mathrm{E} 10$. This band co-migrates with trimers of synthetic $A \beta$ and is considered by some authors as oligomeric- $A \beta[66,67]$. However, the epitope recognized by $6 \mathrm{E} 10$ is shared by the $\mathrm{C}$-terminus fragments of the amyloidogenic pathway $(\beta-\mathrm{CTF})$ and $6 \mathrm{E} 10$ is often used to detect $\beta$-CTF from cell lysates and homogenates [68]. The fact that CTFs migrate around $12 \mathrm{kDa}$, as do $\mathrm{A} \beta$ trimers, complicated the interpretation of the band. To clarify the nature of this material we sought to specifically quantify CTF fragments and human $A \beta$ in the same samples. This analysis also allowed us to determine the relative abundance of the two species in each brain.

Western blots using a specific antibody directed against the C-terminus of full-length APP (pab27576) revealed a reduction in the CTF content, which did not reach significance (Figure 2D and 2E). Even though the band recognized by pab27576 perfectly overlapped with the band seen with $6 \mathrm{E} 10$, the results did not fully match our analysis with 6E10. It is possible that the discrepancy is due to different specificity of the antibodies. Alternatively, some CTF material from the non-amyloidogenic pathway $(\alpha \mathrm{CTF}$ which can be detected by pab27576 but not by 6E10) might have affected our quantification. We also considered the possibility that the $12-\mathrm{kDa}$ band was constituted mostly of $A \beta$ species (trimers) and so performed a highly sensitive ELISA assay for human $A \beta 40$ and $A \beta 42$. No plaques were detected in the animals and, from our previous study in this model, the $A \beta$-ir species are either monomeric or oligomeric at this stage [22]. Therefore, the $A \beta$ material measured via ELISA can be considered as soluble in nature. Our analysis of such soluble $A \beta$ material did reveal some degree of reduction after treatment with minocycline, but the high variability resulted in no statistical significance (Figure $2 \mathrm{~F}$ ). In summary, while the three analyses (western blot with 6E10, pab27576 and ELISA) all showed a reduction of APPrelated products, the pattern observed with the $6 \mathrm{E} 10$ antibody was not fully reproduced by either that of CTF or $\mathrm{A} \beta$ alone. A likely explanation for this is that the 12$\mathrm{kDa}$ band recognized by $6 \mathrm{E} 10$ represents a mixture of $\beta$ $\mathrm{CTF}$ and $\mathrm{A} \beta$-oligomers. In this view, it is possible that minocycline treatment resulted in the reduction of both species, which together reached significance. Nevertheless, further investigations are needed to clarify this point.

The simultaneous presence of $A \beta$ and APP-related products in early, pre-plaque stages of the disease in $\mathrm{Tg}$ models of $\mathrm{AD}$ is a highly controversial issue [69-73]. In particular, their relative abundance and their specific 
contribution to the neuropathology have not been clarified. We therefore took advantage of the data set presented here to explore the relative abundance of $A \beta$ and CTF, and the effect of an anti-inflammatory treatment on their ratio. We compared the absolute levels of CTF (extrapolated from a recombinant CTF calibration curve, using a semi-quantitative method) and $\mathrm{A} \beta$ (measured via ELISA) from each sample. In Tg Placebo animals we observed (on average) $6.76 \mathrm{pg}$ of $\mathrm{A} \beta 40$ per each ng of CTF, and $24 \mathrm{pg}$ of A 442 per each ng of CTF. In terms of molar ratio, it appears that McGill-Thy1-APP mice harbor about 84 molecules of CTF per each molecule of $\mathrm{A} \beta 40$ and about 24 molecules of CTF per each molecule of $A \beta 42$. It is therefore very likely that, while the species co-exist, $\beta$-CTF fragments represent the vast majority of the material seen with $6 \mathrm{E} 10$, as suggested by McAlpine et al. [74].

\section{Beta-site APP cleaving enzyme 1-deregulation in young, pre-plaque mice and its correction with minocycline}

To further elucidate the effect of minocycline on APP processing, we studied the levels and activity of BACE-1, the most important $\beta$-site APP cleaving enzyme in the brain [75].

Our analysis revealed that BACE-1 levels and activity were up-regulated in the McGill-Thy1-APP Tg model, in agreement with reports from sporadic AD [76-79] and Tg models $[24,80,81]$. As described in young V717V $\mathrm{Tg}$ mice [24], BACE-1 levels and activity were up-regulated in McGill-Thy1-APP mice prior to plaque deposition. Therefore, deregulation of APP processing might be an early event in the progression of the AD-like amyloid pathology. Minocycline treatment restored BACE-1 activity to control levels, and corrected BACE-1 protein content in young, pre-plaque Tg mice (Figure 3). These results would agree with the western blotting of $6 \mathrm{E} 10$ (Figure 2) in indicating reduced $\beta$-cleavage of APP upon anti-inflammatory treatment.

Since the anti-inflammatory treatment with minocycline was able to correct BACE-1 up-regulation in preplaque $\mathrm{Tg}$ mice, it is very likely that the early deregulation of BACE-1 prior to plaque deposition is related to the pro-inflammatory process. This view is in line with the body of evidence indicating that neuroinflammation has a pivotal role in regulating BACE-1. In fact, several studies have indicated that BACE- 1 behaves as a stressresponse protein and its levels are increased by cytokines [82], oxidative stress [83], astrocytic activation [84], ischemia [85], hypoxia [86] and energy inhibition [87]. On the other hand, we did not detect any effect of minocycline treatment on the levels of $A \beta$-degrading enzymes such as insulin-degrading enzyme and neprilysin (data not shown).

\section{Minocycline mechanism of action and effect on NFkB}

In an attempt to clarify the mechanism of action of minocycline, we measured the levels of $\mathrm{NFkB}$, a key transcription factor which is known to regulate the expression of several inflammatory markers as well as BACE- 1 and APP $[38,88,89]$. Increased NFkB expression is associated with neuroinflammatory conditions and it has been reported in AD [90-93]. Elevated NFkB activity was detected in Tg models of AD [94]. Interestingly, since the promoter of the IkB gene contains several NFkB binding sites [39], IkB expression is elevated in response to NFkB activation following cerebral ischemia [95] and lipopolysaccharide injections [96]. Increased levels of IkB have also been reported in AD [93].

Consistent with the results from AD samples, we found up-regulated levels of NFkB and its inhibitor, IkB, in Tg animals compared to Non Tg Placebo animals. Given the relatively high variability of the data, these changes did not reach statistical significance; however, they support the notion of a pro-inflammatory state in these brains. Accordingly, NFkB levels were reduced following minocycline treatment, while I $\mathrm{kB}$ was further up-regulated. A reduction of NFkB with concomitant up-regulation of $\mathrm{IkB}$ has been reported for other anti-inflammatory agents such as ibuprofen [97] and for glucocorticoids [98]. The increase in $\mathrm{IkB}$ levels is thought to further potentiate the anti-inflammatory effect, as any NFkB molecule synthesized by the cell will associate with the inhibitor and be prevented from entering the nucleus. These results, even though they did not reach significance, suggested that minocycline treatment in $\mathrm{Tg}$ animals resulted in an overall decreased activity of NFkB.

Furthermore, the levels of NFkB strongly correlated with BACE-1 levels in each sample. These results are consistent with the concept that BACE-1 levels and activity are tightly linked to NFkB levels in vivo. Even though this type of correlative analysis cannot prove causality, several indications exist that NFkB regulates BACE in vivo. Paris et al. have recently shown that the NFkB inhibitor celastrol is capable of inhibiting BACE and reducing amyloidogenic pathway in a mouse Tg model of AD [99]. Similarly, a reduction in BACE- 1 and $A \beta$ levels was found in Tg mice acutely treated with the NSAID ibuprofen [100]. This drug is endowed with multiple COX- independent mechanisms of action, including inhibition of NFkB signaling [101], peroxisome proliferator activated receptor-gamma activation [82] and gamma-secretase modulation [41]. It is very likely that, like ibuprofen, minocycline exerts its beneficial effects via multiple mechanisms of action.

Based on our results, one could speculate that the inflammation-induced hyperactivity of NFkB is responsible for the increased transcription of BACE-1 in Tg animals. This might represent a possible mechanism for 
the glia-to-neuron or neuron-to-glia communication in early $\mathrm{AD}$, whereby the activation state of microglia can instruct the processing of APP in neurons. Alternatively, the reduction of inflammatory markers and the reduction in BACE-1 (levels and activity) following minocycline treatment might be parallel, unrelated events sharing the same up-stream events (that is, inhibition of NFkB in glia and neurons).

\section{Minocycline adverse effects}

It is important to note that the intraperitoneal application of $50 \mathrm{mg} / \mathrm{Kg} /$ day of minocycline resulted in some toxicity: one out of eight mice (12.5\%) in the Non $\mathrm{Tg}$ group and two out of seven mice $(28 \%)$ in the Tg group died, while the remaining mice showed signs of liver toxicity and peritoneal irritation. These adverse effects precluded the completion of behavioral testing for learning and memory, such as the Morris water maze task. Liver toxicity [102] and peritoneal inflammation [103] are known side effects of intraperitoneal administration of minocycline which are seldom referred to in numerous experimental published studies. It has been established that the peripheral inflammatory process can have an impact on the microglial status in the CNS $[104,105]$. Indeed, the occurrence of some glial activation following minocycline treatment is supported by the rise in NFkB levels and BACE-1 activity in the Non $\mathrm{Tg}$ Mino group. However, these alterations were not accompanied by classical pro-inflammatory activity, as COX-2, iNOS and IL- $1 \beta$ were not found to be significantly different from Non Tg Placebo. As the intraperitoneal application of the drug was not inert, we cannot rule out the possibility that peripheral toxicity could have had some role in the CNS effects observed in the Tg-treated mice.

While the dose and administration route of the drug need to be optimized to avoid adverse peripheral effects, our overall results indicate that the inhibition of neuroinflammation with minocycline can be beneficial in early pre-plaque stages of AD-like amyloid pathology.

\section{Conclusions}

This report demonstrates that the early, pre-plaque inflammatory process occurring at the initial stages of AD-like amyloid pathology can be modulated pharmacologically by the application of minocycline. The downregulation of inflammatory markers was accompanied by a reduction of APP levels and correction of BACE-1 hyperactivity. Our results indicate that inflammation has a pivotal role in the early stages of the disease, including the modulation of APP metabolism. Interfering with inflammation could be a useful therapeutic approach in early, pre-plaque stages of AD-like amyloid pathology.

\section{Abbreviations}

AD: Alzheimer's disease; $A B$ : Amyloid- $\beta$ peptide; ANOVA: Analysis of variance; APP: Amyloid precursor protein; BACE: $\beta$-site APP cleaving enzyme; CNS: Central nervous system; COX-2: Cyclooxygenase 2; CTF: C-terminus fragment; DMEM: Dulbecco's modified Eagle's medium; ELISA: Enzyme-linked immunosorbent assay; FBS: Fetal bovine serum; flap: Full-length amyloid precursor protein; HRP: Horseradish peroxidase; Iba-1: Ionized calciumbinding adaptor molecule 1 ; iNOS: Inducible nitric oxide synthase; IL-1 $\beta$ : Interleukin-1 beta; IkB: inhibitor of NFkB; Ir: Immunoreactivity; MCI: Mild cognitive impairment; NFkB: Nuclear factor kappa B; NSAID: Nonsteroidal anti-inflammatory drugs; PBS: Phosphate-buffered saline; TBS: Tris-buffered saline; Tg: Transgenic.

\section{Acknowledgements}

We sincerely thank Dr G. Multhaup, Freie University, Berlin, for the generous gift of the pab27576 and the recombinant C100 and discussions. We also thank Dr D. Maysinger (McGill University) for sharing of equipment. MTF is the holder of a Programme de Bourse d'Excellence pour Étudiants Étrangers from the Fonds de Recherche sur la Nature et les Technologies du Québec. ACC is the holder of the Charles E. Frosst/Merck-endowed Chair in Pharmacology. This work was funded by CIHR (MOP-67170), and ISOA (grant number 271224) to ACC. The ACC laboratory is grateful for the unrestricted support received from Dr A. Frosst, the Frosst family and Merck Canada.

\section{Author details}

${ }^{1}$ Department of Pharmacology and Therapeutics, McGill University, 3655 Promenade Sir-William-Osler, Room 1210, Montreal, QC H3G 1Y6, Canada. 2Department of Anatomy and Cell Biology, McGill University, Montreal, QC H3A 2B2, Canada. ${ }^{3}$ Department of Neurology and Neurosurgery, McGill University, Montreal, QC H3A 2B4, Canada.

\section{Authors' contributions}

MTF designed the experiment, carried out the intraperitoneal injections, the western blotting, the Iba-1 study of microglia morphology and BACE activity assays and drafted the manuscript. SA helped in the treatment of the animals and the collection of material for immunohistochemistry; he made substantial contributions to the interpretation of results and finalizing the manuscript. VP was involved in the treatment of the animals, performed all the perfusions and collected the material for immunohistochemistry. AD was responsible for the breeding of transgenic animals and performed all the genotyping. ACC provided intellectual guidance in the experimental design, interpretation of the results and on the editing the manuscript. All authors read and approved the final version of the manuscript.

\section{Competing interests}

The authors declare that they have no competing interests.

Received: 24 October 2011 Accepted: 2 April 2012

Published: 2 April 2012

\section{References}

1. Wimo A, Prince M: World Alzheimer Report 2010 London: Alzheimer's Disease International; 2010

2. Iqbal K, Grundke-lqbal I: Alzheimer neurofibrillary degeneration: significance, etiopathogenesis, therapeutics and prevention. J Cell Mol Med 2008, 12:38-55.

3. Selkoe DJ: The genetics and molecular pathology of Alzheimer's disease: roles of amyloid and the presenilins. Neurol Clin 2000, 18:903-922.

4. Vassar R, Bennett BD, Babu-Khan S, Kahn S, Mendiaz EA, Denis P, Teplow DB, Ross S, Amarante P, Loeloff R, Luo Y, Fisher S, Fuller J, Edenson S, Lile J, Jarosinski MA, Biere AL, Curran E, Burgess T, Louis JC, Collins F, Treanor J, Rogers G, Citron M: Beta-secretase cleavage of Alzheimer's amyloid precursor protein by the transmembrane aspartic protease BACE. Science 1999, 286:735-741.

5. Wolfe MS, Xia W, Ostaszewski BL, Diehl TS, Kimberly WT, Selkoe DJ: Two transmembrane aspartates in presenilin-1 required for presenilin endoproteolysis and gamma-secretase activity. Nature 1999, 398:513-517.

6. Glabe CC: Amyloid accumulation and pathogenesis of Alzheimer's disease: significance of monomeric, oligomeric and fibrillar Abeta. Subcell Biochem 2005, 38:167-177. 
7. Akiyama H, Barger S, Barnum S, Bradt B, Bauer J, Cole GM, Cooper NR, Eikelenboom P, Emmerling M, Fiebich BL, Finch CE, Frautschy S, Griffin WS, Hampel H, Hull M, Landreth G, Lue L, Mrak R, Mackenzie IR, McGeer PL, O'Banion MK, Pachter J, Pasinetti G, Plata-Salaman C, Rogers J, Rydel R, Shen Y, Streit W, Strohmeyer R, Tooyoma I, Van Muiswinkel FL, Veerhuis R, Walker D, Webster S, Wegrzyniak B, Wenk G, Wyss-Coray T: Inflammation and Alzheimer's disease. Neurobiol Aging 2000, 21:383-421.

8. Schwartz M, Shechter R: Systemic inflammatory cells fight off neurodegenerative disease. Nat Rev Neurol 2010, 6:405-410.

9. Floden AM, Li S, Combs CK: Beta-amyloid-stimulated microglia induce neuron death via synergistic stimulation of tumor necrosis factor alpha and NMDA receptors. J Neurosci 2005, 25:2566-2575.

10. Morgan D, Gordon MN, Tan J, Wilcock D, Rojiani AM: Dynamic complexity of the microglial activation response in transgenic models of amyloid deposition: implications for Alzheimer therapeutics. J Neuropathol Exp Neurol 2005, 64:743-753.

11. Wyss-Coray T: Inflammation in Alzheimer disease: driving force, bystander or beneficial response? Nat Med 2006, 12:1005-1015.

12. Aisen PS, Schafer KA, Grundman M, Pfeiffer E, Sano M, Davis KL, Farlow MR, Jin S, Thomas RG, Thal LJ: Effects of rofecoxib or naproxen vs placebo on Alzheimer disease progression: a randomized controlled trial. JAMA 2003, 289:2819-2826.

13. Thal LJ, Ferris SH, Kirby L, Block GA, Lines CR, Yuen E, Assaid C, Nessly ML, Norman BA, Baranak CC, Reines SA, Rofecoxib Protocol 078 study group: A randomized, double-blind, study of rofecoxib in patients with mild cognitive impairment. Neuropsychopharmacology 2005, 30:1204-1215.

14. Soininen $H$, West C, Robbins J, Niculescu L: Long-term efficacy and safety of celecoxib in Alzheimer's disease. Dement Geriatr Cogn Disord 2007, 23:8-21.

15. McGeer PL, McGeer EG: NSAIDs and Alzheimer disease: epidemiological, animal model and clinical studies. Neurobiol Aging 2007, 28:639-647.

16. Okello A, Edison P, Archer HA, Turkheimer FE, Kennedy J, Bullock R, Walker Z, Kennedy A, Fox N, Rossor M, Brooks DJ: Microglial activation and amyloid deposition in mild cognitive impairment: a PET study. Neurology 2009, 72:56-62.

17. Parachikova A, Agadjanyan MG, Cribbs DH, Blurton-Jones M, Perreau V, Rogers J, Beach TG, Cotman CW: Inflammatory changes parallel the early stages of Alzheimer disease. Neurobiol Aging 2007, 28:1821-1833.

18. Bruno MA, Mufson EJ, Wuu J, Cuello AC: Increased matrix metalloproteinase 9 activity in mild cognitive impairment. J Neuropathol Exp Neurol 2009, 68:1309-1318.

19. Ferretti MT, Cuello AC: Does a pro-inflammatory process precede Alzheimer's disease and mild cognitive impairment? Curr Alzheimer Res 2011, 8:164-174.

20. Griffin WS, Stanley LC, Ling C, White L, MacLeod V, Perrot L, White CL III, Araoz C: Brain interleukin 1 and S-100 immunoreactivity are elevated in Down syndrome and Alzheimer disease. Proc Natl Acad Sci USA 1989, 86:7611-7615

21. Ashe KH, Zahs KR: Probing the biology of Alzheimer's disease in mice. Neuron 2010, 66:631-645.

22. Ferretti MT, Partridge V, Leon WC, Canneva F, Allard S, Arvanitis DN, Vercauteren F, Houle D, Ducatenzeiler A, Klein WL, Glabe CG, Szyf M, Cuello AC: Transgenic mice as a model of pre-clinical Alzheimer's disease. Curr Alzheimer Res 2011, 8:4-23.

23. Ferretti MT, Bruno MA, Ducatenzeiler A, Klein WL, Cuello AC: Intracellular Abeta-oligomers and early inflammation in a model of Alzheimer's disease. Neurobiol Aging 2011.

24. Heneka MT, Sastre M, Dumitrescu-Ozimek L, Dewachter I, Walter J, Klockgether T, van Leuven F: Focal glial activation coincides with increased BACE1 activation and precedes amyloid plaque deposition in APP[V717l] transgenic mice. J Neuroinflammation 2005, 2:22.

25. Varvel NH, Bhaskar K, Kounnas MZ, Wagner SL, Yang Y, Lamb BT, Herrup K. NSAIDs prevent, but do not reverse, neuronal cell cycle reentry in a mouse model of Alzheimer disease. J Clin Invest 2009, 119:3692-3702.

26. Janelsins MC, Mastrangelo MA, Oddo S, LaFerla FM, Federoff HJ, Bowers WJ: Early correlation of microglial activation with enhanced tumor necrosis factor-alpha and monocyte chemoattractant protein-1 expression specifically within the entorhinal cortex of triple transgenic Alzheimer's disease mice. J Neuroinflammation 2005, 2:23.

27. Cornet S, Spinnewyn B, Delaflotte S, Charnet C, Roubert V, Favre C, Hider H, Chabrier PE, Auguet M: Lack of evidence of direct mitochondrial involvement in the neuroprotective effect of minocycline. Eur $J$ Pharmacol 2004, 505:111-119.

28. Fan R, Xu F, Previti ML, Davis J, Grande AM, Robinson JK, van Nostrand WE: Minocycline reduces microglial activation and improves behavioral deficits in a transgenic model of cerebral microvascular amyloid. J Neurosci 2007, 27:3057-3063.

29. Du Y, Ma Z, Lin S, Dodel RC, Gao F, Bales KR, Triarhou LC, Chernet E, Perry KW, Nelson DL, Luecke S, Phebus LA, Bymaster FP, Paul SM: Minocycline prevents nigrostriatal dopaminergic neurodegeneration in the MPTP model of Parkinson's disease. Proc Natl Acad Sci USA 2001, 98:14669-14674.

30. Hu L, Wong TP, Cote SL, Bell KF, Cuello AC: The impact of Abeta-plaques on cortical cholinergic and non-cholinergic presynaptic boutons in Alzheimer's disease-like transgenic mice. Neuroscience 2003, 121:421-432.

31. Côté S, Ribeiro-da-Silva A, Cuello AC: Current protocols for light microscopy immunocytochemistry. In Immunohistochemistry II. Edited by: Cuello AC. Chichester: John Wiley 1993:147-168.

32. Franklin KBJ, Paxinos G: The Mouse Brain in Stereotaxic Coordinates San Diego: Academic; 1997

33. Kaushal V, Schlichter LC: Mechanisms of microglia-mediated neurotoxicity in a new model of the stroke penumbra. J Neurosci 2008, 28:2221-2230.

34. Ahmed Z, Shaw G, Sharma VP, Yang C, McGowan E, Dickson DW: Actinbinding proteins coronin-1a and IBA-1 are effective microglial markers for immunohistochemistry. J Histochem Cytochem 2007, 55:687-700.

35. Lawson $\sqcup$, Perry VH, Dri P, Gordon S: Heterogeneity in the distribution and morphology of microglia in the normal adult mouse brain. Neuroscience 1990, 39:151-170.

36. Wirths O, Multhaup G, Czech C, Feldmann N, Blanchard V, Tremp G, Beyreuther K, Pradier L, Bayer TA: Intraneuronal APP/A beta trafficking and plaque formation in beta-amyloid precursor protein and presenilin-1 transgenic mice. Brain Pathol 2002, 12:275-286.

37. Baeuerle PA, Henkel T: Function and activation of NF-kappa B in the immune system. Annu Rev Immunol 1994, 12:141-179.

38. Kaltschmidt B, Widera D, Kaltschmidt C: Signaling via NF-kappaB in the nervous system. Biochim Biophys Acta 2005, 1745:287-299.

39. Sun SC, Ganchi PA, Ballard DW, Greene WC: NF-kappa B controls expression of inhibitor I kappa B alpha: evidence for an inducible autoregulatory pathway. Science 1993, 259:1912-1915.

40. Lim GP, Yang F, Chu T, Chen P, Beech W, Teter B, Tran T, Ubeda O, Ashe KH, Frautschy SA, Cole GM: Ibuprofen suppresses plaque pathology and inflammation in a mouse model for Alzheimer's disease. J Neurosci 2000, 20:5709-5714.

41. Weggen $S$, Eriksen JL, Das $P$, Sagi $S A$, Wang R, Pietrzik CU, Findlay KA, Smith TE, Murphy MP, Bulter T, Kang DE, Marquez-Sterling N, Golde TE, Koo EH: A subset of NSAIDs lower amyloidogenic Abeta42 independently of cyclooxygenase activity. Nature 2001, 414:212-216.

42. Yan Q, Zhang J, Liu H, Babu-Khan S, Vassar R, Biere AL, Citron M, Landreth G: Anti-inflammatory drug therapy alters beta-amyloid processing and deposition in an animal model of Alzheimer's disease. $J$ Neurosci 2003, 23:7504-7509.

43. McGeer PL, McGeer E, Rogers J, Sibley J: Anti-inflammatory drugs and Alzheimer disease. Lancet 1990, 335:1037.

44. Andersen K, Launer LJ, Ott A, Hoes AW, Breteler MM, Hofman A: Do nonsteroidal anti-inflammatory drugs decrease the risk for Alzheimer's disease? The Rotterdam Study. Neurology 1995, 45:1441-1445.

45. Stewart WF, Kawas C, Corrada M, Metter EJ: Risk of Alzheimer's disease and duration of NSAID use. Neurology 1997, 48:626-632.

46. Klegeris A, McGeer PL: Non-steroidal anti-inflammatory drugs (NSAIDs) and other anti-inflammatory agents in the treatment of neurodegenerative disease. Curr Alzheimer Res 2005, 2:355-365.

47. Lyketsos CG, Breitner JC, Green RC, Martin BK, Meinert C, Piantadosi S, Sabbagh M: Naproxen and celecoxib do not prevent $A D$ in early results from a randomized controlled trial. Neurology 2007, 68:1800-1808.

48. ADAPT Research Group: Cognitive function over time in the Alzheimer's Disease Anti-inflammatory Prevention Trial (ADAPT): results of a randomized, controlled trial of naproxen and celecoxib. Arch Neurol 2008, 65:896-905.

49. Breitner JC, Baker LD, Montine TJ, Meinert CL, Lyketsos CG, Ashe KH, Brandt J, Craft S, Evans DE, Green RC, Ismail MS, Martin BK, Mullan MJ, Sabbagh M, Tariot PN, ADAPT Research Group: Extended results of the 
Alzheimer's disease anti-inflammatory prevention trial. Alzheimers Dement 2011, 7:402-411.

50. Leoutsakos JM, Muthen BO, Breitner JC, Lyketsos CG: Effects of nonsteroidal anti-inflammatory drug treatments on cognitive decline vary by phase of pre-clinical Alzheimer disease: findings from the randomized controlled Alzheimer's Disease Anti-inflammatory Prevention Trial. Int J Geriatr Psychiatry 2011.

51. Keller AF, Gravel M, Kriz J: Treatment with minocycline after disease onset alters astrocyte reactivity and increases microgliosis in SOD1 mutant mice. Exp Neurol 2011, 228:69-79

52. Griffin MO, Fricovsky E, Ceballos G, Villarreal F: Tetracyclines: a pleitropic family of compounds with promising therapeutic properties. Review of the literature. Am J Physiol Cell Physiol 2010, 299:C539-C548.

53. Jordan J, Fernandez-Gomez FJ, Ramos M, Ikuta I, Aguirre N, Galindo MF: Minocycline and cytoprotection: shedding new light on a shadowy controversy. Curr Drug Deliv 2007, 4:225-231.

54. Parachikova A, Vasilevko V, Cribbs DH, LaFerla FM, Green KN: Reductions in amyloid-beta-derived neuroinflammation, with minocycline, restore cognition but do not significantly affect tau hyperphosphorylation. J Alzheimers Dis 2010, 21:527-542.

55. Choi Y, Kim HS, Shin KY, Kim EM, Kim M, Kim HS, Park CH, Jeong YH, Yoo J, Lee JP, Chang KA, Kim S, Suh YH: Minocycline attenuates neuronal cell death and improves cognitive impairment in Alzheimer's disease models. Neuropsychopharmacology 2007, 32:2393-2404

56. Seabrook TJ, Jiang L, Maier M, Lemere CA: Minocycline affects microglia activation, Abeta deposition, and behavior in APP-tg mice. Glia 2006, 53:776-782.

57. Town T, Nikolic $V$, Tan J: The microglial "activation" continuum: from innate to adaptive responses. J Neuroinflammation 2005, 2:24.

58. Colton CA, Mott RT, Sharpe H, Xu Q, Van Nostrand WE, Vitek MP: Expression profiles for macrophage alternative activation genes in $A D$ and in mouse models of AD. J Neuroinflammation 2006, 3:27.

59. Tan J, Town T, Mori T, Wu Y, Saxe M, Crawford F, Mullan M: CD45 opposes beta-amyloid peptide-induced microglial activation via inhibition of $\mathrm{p} 44 /$ 42 mitogen-activated protein kinase. J Neurosci 2000, 20:7587-7594.

60. Zhu Y, Hou H, Rezai-Zadeh K, Giunta B, Ruscin A, Gemma C, Jin J, Dragicevic N, Bradshaw P, Rasool S, Glabe CG, Ehrhart J, Bickford P, Mori T, Obregon D, Town T, Tan J: CD45 deficiency drives amyloid- $\beta$ peptide oligomers and neuronal loss in Alzheimer's disease mice. J Neurosci 2011, 31:1355-1365.

61. McLean CA, Cherny RA, Fraser FW, Fuller SJ, Smith MJ, Beyreuther K, Bush Al, Masters CL: Soluble pool of Abeta amyloid as a determinant of severity of neurodegeneration in Alzheimer's disease. Ann Neurol 1999, 46:860-866.

62. Terry RD, Masliah E, Salmon DP, Butters N, DeTeresa R, Hill R, Hansen LA Katzman R: Physical basis of cognitive alterations in Alzheimer's disease: synapse loss is the major correlate of cognitive impairment. Ann Neurol 1991, 30:572-580.

63. Gomez-Isla T, Hollister R, West H, Mui S, Growdon JH, Petersen RC, Parisi JE, Hyman BT: Neuronal loss correlates with but exceeds neurofibrillary tangles in Alzheimer's disease. Ann Neurol 1997, 41:17-24.

64. Forloni G, Demicheli F, Giorgi S, Bendotti C, Angeretti N: Expression of amyloid precursor protein mRNAs in endothelial, neuronal and glial cells: modulation by interleukin-1. Brain Res Mol Brain Res 1992, 16:128-134.

65. Griffin WS, Liu L, Li Y, Mrak RE, Barger SW: Interleukin-1 mediates Alzheimer and Lewy body pathologies. J Neuroinflammation 2006, 3:5.

66. McLaurin J, Kierstead ME, Brown ME, Hawkes CA, Lambermon MH, Phinney AL, Darabie AA, Cousins JE, French JE, Lan MF, Lan MF, Chen F, Wong SS, Mount HT, Fraser PE, Westaway D, St George-Hyslop P: Cyclohexanehexol inhibitors of Abeta aggregation prevent and reverse Alzheimer phenotype in a mouse model. Nat Med 2006, 12:801-808.

67. Lesne S, Koh MT, Kotilinek L, Kayed R, Glabe CG, Yang A, Gallagher M, Ashe $\mathrm{KH}: \mathrm{A}$ specific amyloid-beta protein assembly in the brain impairs memory. Nature 2006, 440:352-357.

68. Sastre M: Troubleshooting methods for APP processing in vitro. J Pharmacol Toxicol Methods 2010, 61:86-91.

69. Wirths O, Multhaup G, Czech C, Blanchard V, Moussaoui S, Tremp G, Pradier L, Beyreuther K, Bayer TA: Intraneuronal Abeta accumulation precedes plaque formation in beta-amyloid precursor protein and presenilin-1 double-transgenic mice. Neurosci Lett 2001, 306:116-120.
70. Rosario ER, Carroll JC, Oddo S, LaFerla FM, Pike CJ: Androgens regulate the development of neuropathology in a triple transgenic mouse model of Alzheimer's disease. J Neurosci 2006, 26:13384-13389.

71. Philipson O, Lannfelt L, Nilsson LN: Genetic and pharmacological evidence of intraneuronal Abeta accumulation in APP transgenic mice. FEBS Lett 2009, 583:3021-3026.

72. Aho L, Pikkarainen M, Hiltunen M, Leinonen V, Alafuzoff I: Immunohistochemical visualization of amyloid-beta protein precursor and amyloid-beta in extra- and intracellular compartments in the human brain. J Alzheimers Dis 2010, 20:1015-1028.

73. Winton MJ, Lee EB, Sun E, Wong MM, Leight S, Zhang B, Trojanowski JQ, Lee VM: Intraneuronal APP, not free A $\beta$ peptides in $3 \times$ Tg-AD mice: implications for tau versus $A \beta$-mediated Alzheimer neurodegeneration. $J$ Neurosci 2011, 31:7691-7699.

74. McAlpine FE, Lee JK, Harms AS, Ruhn KA, Blurton-Jones M, Hong J, Das P, Golde TE, LaFerla FM, Oddo S, Blesch A, Tansey MG: Inhibition of soluble TNF signaling in a mouse model of Alzheimer's disease prevents preplaque amyloid-associated neuropathology. Neurobiol Dis 2009, 34:163-177.

75. Vassar R: BACE1: the beta-secretase enzyme in Alzheimer's disease. J Mol Neurosci 2004, 23:105-114.

76. Fukumoto H, Cheung BS, Hyman BT, Irizarry MC: Beta-secretase protein and activity are increased in the neocortex in Alzheimer disease. Arch Neurol 2002, 59:1381-1389.

77. Yang LB, Lindholm K, Yan R, Citron M, Xia W, Yang XL, Beach T, Sue L, Wong P, Price D, Shen Y: Elevated beta-secretase expression and enzymatic activity detected in sporadic Alzheimer disease. Nat Med 2003, 9:3-4.

78. Li R, Lindholm $K$, Yang LB, Yue $X$, Citron $M$, Yan R, Beach $T$, Sue L, Sabbagh M, Cai H, Wong P, Price D, Shen Y: Amyloid beta peptide load is correlated with increased beta-secretase activity in sporadic Alzheimer's disease patients. Proc Natl Acad Sci USA 2004, 101:3632-3637.

79. Harada H, Tamaoka A, Ishii K, Shoji S, Kametaka S, Kametani F, Saito Y, Murayama S: Beta-site APP cleaving enzyme 1 (BACE1) is increased in remaining neurons in Alzheimer's disease brains. Neurosci Res 2006, 54:24-29.

80. Zhao J, Fu Y, Yasvoina M, Shao P, Hitt B, O'Connor T, Logan S, Maus E, Citron $M$, Berry $R$, Binder L, Vassar R: Beta-site amyloid precursor protein cleaving enzyme 1 levels become elevated in neurons around amyloid plaques: implications for Alzheimer's disease pathogenesis. J Neurosci 2007, 27:3639-3649.

81. O'Connor T, Sadleir KR, Maus E, Velliquette RA, Zhao J, Cole SL, Eimer WA, Hitt B, Bembinster LA, Lammich S, Lichtenthaler SF, Hébert SS, De Strooper B, Haass C, Bennett DA, Vassar R: Phosphorylation of the translation initiation factor elF2alpha increases BACE1 levels and promotes amyloidogenesis. Neuron 2008, 60:988-1009.

82. Sastre M, Dewachter I, Landreth GE, Willson TM, Klockgether T, Van Leuven F, Heneka MT: Nonsteroidal anti-inflammatory drugs and peroxisome proliferator-activated receptor-gamma agonists modulate immunostimulated processing of amyloid precursor protein through regulation of beta-secretase. J Neurosci 2003, 23:9796-9804.

83. Tamagno E, Bardini P, Obbili A, Vitali A, Borghi R, Zaccheo D, Pronzato MA Danni O, Smith MA, Perry G, Tabaton M: Oxidative stress increases expression and activity of BACE in NT2 neurons. Neurobiol Dis 2002, 10:279-288.

84. Mori T, Koyama N, Arendash GW, Horikoshi-Sakuraba Y, Tan J, Town T: Overexpression of human $\mathrm{S} 100 \mathrm{~B}$ exacerbates cerebral amyloidosis and gliosis in the Tg2576 mouse model of Alzheimer's disease. Glia 2010, 58:300-314.

85. Wen Y, Onyewuchi O, Yang S, Liu R, Simpkins JW: Increased beta-secretase activity and expression in rats following transient cerebral ischemia. Brain Res 2004, 1009:1-8.

86. Webster NJ, Green KN, Peers C, Vaughan PF: Altered processing of amyloid precursor protein in the human neuroblastoma SH-SY5Y by chronic hypoxia. J Neurochem 2002, 83:1262-1271.

87. Velliquette RA, O'Connor T, Vassar R: Energy inhibition elevates betasecretase levels and activity and is potentially amyloidogenic in APP transgenic mice: possible early events in Alzheimer's disease pathogenesis. J Neurosci 2005, 25:10874-10883. 
88. Rossner S, Sastre M, Bourne K, Lichtenthaler SF: Transcriptional and translational regulation of BACE1 expression-implications for Alzheimer's disease. Prog Neurobiol 2006, 79:95-111.

89. Grilli M, Ribola M, Alberici A, Valerio A, Memo M, Spano P: Identification and characterization of a kappa $\mathrm{B} /$ Rel binding site in the regulatory region of the amyloid precursor protein gene. J Biol Chem 1995, 270:26774-26777.

90. Terai K, Matsuo A, McGeer PL: Enhancement of immunoreactivity for NFkappa B in the hippocampal formation and cerebral cortex of Alzheimer's disease. Brain Res 1996, 735:159-168.

91. Kaltschmidt B, Uherek M, Volk B, Baeuerle PA, Kaltschmidt C: Transcription factor NF-kappaB is activated in primary neurons by amyloid beta peptides and in neurons surrounding early plaques from patients with Alzheimer disease. Proc Natl Acad Sci USA 1997, 94:2642-2647.

92. Ferrer I, Marti E, Lopez E, Tortosa A: NF-kB immunoreactivity is observed in association with beta A4 diffuse plaques in patients with Alzheimer's disease. Neuropathol Appl Neurobiol 1998, 24:271-277.

93. Yoshiyama Y, Arai K, Hattori T: Enhanced expression of I-kappaB with neurofibrillary pathology in Alzheimer's disease. Neuroreport 2001, 12:2641-2645.

94. Sung S, Yang H, Uryu K, Lee EB, Zhao L, Shineman D, Trojanowski JQ, Lee VM, Pratico D: Modulation of nuclear factor-kappa B activity by indomethacin influences $A$ beta levels but not $A$ beta precursor protein metabolism in a model of Alzheimer's disease. Am J Pathol 2004, 165:2197-2206.

95. Aronowski J, Strong R, Kang HS, Grotta JC: Selective up-regulation of I kappaB-alpha in ischemic penumbra following focal cerebral ischemia. Neuroreport 2000, 11:1529-1533.

96. Zhang J, Rivest S: Anti-inflammatory effects of prostaglandin E2 in the central nervous system in response to brain injury and circulating lipopolysaccharide. J Neurochem 2001, 76:855-864.

97. Heneka MT, Gavrilyuk V, Landreth GE, O'Banion MK, Weinberg G, Feinstein DL: Noradrenergic depletion increases inflammatory responses in brain: effects on IkappaB and HSP70 expression. J Neurochem 2003, 85:387-398.

98. Scheinman Rl, Cogswell PC, Lofquist AK, Baldwin AS Jr: Role of transcriptional activation of I kappa B alpha in mediation of immunosuppression by glucocorticoids. Science 1995, 270:283-286.

99. Paris D, Ganey NJ, Laporte V, Patel NS, Beaulieu-Abdelahad D, Bachmeier C, March A, it-Ghezala G, Mullan MJ: Reduction of beta-amyloid pathology by celastrol in a transgenic mouse model of Alzheimer's disease. $J$ Neuroinflammation 2010, 7:17.

100. Heneka MT, Sastre M, Dumitrescu-Ozimek L, Hanke A, Dewachter I, Kuiperi C, O'Banion K, Klockgether T, van Leuven F, Landreth GE: Acute treatment with the PPARgamma agonist pioglitazone and ibuprofen reduces glial inflammation and Abeta1-42 levels in APPV717I transgenic mice. Brain 2005, 128:1442-1453.

101. Tegeder I, Pfeilschifter J, Geisslinger G: Cyclooxygenase-independent actions of cyclooxygenase inhibitors. FASEB J 2001, 15:2057-2072.

102. Bocker R, Estler CJ, Ludewig-Sandig D: Evaluation of the hepatotoxic potential of minocycline. Antimicrob Agents Chemother 1991, 35:1434-1436.

103. Fagan SC, Edwards DJ, Borlongan CV, Xu L, Arora A, Feuerstein G, Hess DC: Optimal delivery of minocycline to the brain: implication for human studies of acute neuroprotection. Exp Neurol 2004, 186:248-251.

104. Zhang J, Rivest S: Distribution, regulation and colocalization of the genes encoding the EP2- and EP4-PGE2 receptors in the rat brain and neuronal responses to systemic inflammation. Eur J Neurosci 1999, 11:2651-2668.

105. Qin L, Wu X, Block ML, Liu Y, Breese GR, Hong JS, Knapp DJ, Crews FT: Systemic LPS causes chronic neuroinflammation and progressive neurodegeneration. Glia 2007, 55:453-462.

\section{doi:10.1186/1742-2094-9-62}

Cite this article as: Ferretti et al: Minocycline corrects early, pre-plaque neuroinflammation and inhibits BACE- 1 in a transgenic model of Alzheimer's disease-like amyloid pathology. Journal of Neuroinflammation 2012 9:62.

\section{Submit your next manuscript to BioMed Central and take full advantage of:}

- Convenient online submission

- Thorough peer review

- No space constraints or color figure charges

- Immediate publication on acceptance

- Inclusion in PubMed, CAS, Scopus and Google Scholar

- Research which is freely available for redistribution 